Keywords: cabozantinib; metastatic melanoma; uveal melanoma; vascular endothelial growth factor receptor; MET/VEGFR inhibitor; bone metastases

\title{
Phase II randomised discontinuation trial of the MET/VEGF receptor inhibitor cabozantinib in metastatic melanoma
}

\begin{abstract}
Adil Daud*,1, Harriet M Kluger ${ }^{2}$, Razelle Kurzrock ${ }^{3}$, Frauke Schimmoller ${ }^{4,9}$, Aaron L Weitzman ${ }^{4,9}$, Thomas A Samuel ${ }^{5}$, Ali H Moussa ${ }^{6}$, Michael S Gordon ${ }^{7}$ and Geoffrey I Shapiro 8

${ }^{1}$ University of California, San Francisco Medical Center at Parnassus, 1600 Divisadero Street, MZ Bldg A, San Francisco, CA 94115, USA; ${ }^{2}$ Yale Cancer Center, Yale University School of Medicine, 333 Cedar Street, PO Box 208028, New Haven, CT 06520-8028, USA; ${ }^{3}$ University of California, San Diego Moores Cancer Center, 3855 Health Sciences Drive, MC \#0658, La Jolla, CA 92093-0658, USA; ${ }^{4}$ Exelixis Inc., 210 E. Grand Avenue, South San Francisco, CA 94080, USA; ${ }^{5}$ Department of Hematology/Oncology, Cleveland Clinic Florida, 2950 Cleveland Clinic Blvd, Weston, FL 33331, USA; ${ }^{6}$ Cancer Care Associates, 1810 E 15th Street, Tulsa, OK 74104, USA; ${ }^{7}$ Pinnacle Oncology Hematology, 9055 E. Del Camino, Suite 100, Scottsdale, AZ 85258, USA and ${ }^{8}$ Department of Medical Oncology, Dana-Farber Cancer Institute, Early Drug Development Center, 450 Brookline Avenue, Boston, MA 02215, USA
\end{abstract}

Background: A phase II randomised discontinuation trial assessed cabozantinib (XL184), an orally bioavailable inhibitor of tyrosine kinases including VEGF receptors, MET, and AXL, in a cohort of patients with metastatic melanoma.

Methods: Patients received cabozantinib $100 \mathrm{mg}$ daily during a 12-week lead-in. Patients with stable disease (SD) per Response Evaluation Criteria in Solid Tumours (RECIST) at week 12 were randomised to cabozantinib or placebo. Primary endpoints were objective response rate (ORR) at week 12 and postrandomisation progression-free survival (PFS).

Results: Seventy-seven patients were enroled (62\% cutaneous, 30\% uveal, and $8 \%$ mucosal). At week 12 , the ORR was $5 \%$; $39 \%$ of patients had SD. During the lead-in phase, reduction in target lesions from baseline was seen in $55 \%$ of evaluable patients overall and in $59 \%$ of evaluable patients with uveal melanoma. Median PFS after randomisation was 4.1 months with cabozantinib and 2.8 months with placebo (hazard ratio of $0.59 ; P=0.284$ ). Median PFS from study day 1 was 3.8 months, 6 -month PFS was $33 \%$, and median overall survival was 9.4 months. The most common grade $3 / 4$ adverse events were fatigue (14\%), hypertension (10\%), and abdominal pain (8\%). One treatment-related death was reported from peritonitis due to diverticular perforation.

Conclusions: Cabozantinib has clinical activity in patients with metastatic melanoma, including uveal melanoma. Further clinical investigation is warranted.

Historically, metastatic melanoma has been a challenging disease to manage, with traditional chemotherapy having no effect on the median survival time of 6-10 months (Tsao et al, 2004). A number of new therapies for the treatment of stage 4 melanoma have recently become available, including the immuno-oncology agents ipilimumab, nivolumab, and pembrolizumab (Hodi et al, 2010;
Robert et al, 2014, 2015), as well as inhibitors of protein kinases BRAF and mitogen-activated protein kinase (MAPK)/ERK kinase (MEK) for use in patients with activating mutations in BRAF (Hauschild et al, 2012; Sosman et al, 2012; Larkin et al, 2014; Long et al, 2014). Although these new agents have extended median progression-free survival (PFS) and overall survival (OS) in the

*Correspondence: Professor A Daud; E-mail: adaud@medicine.ucsf.edu

Preliminary data from this study were presented in part at the American Society of Clinical Oncology (ASCO) Annual 2013 Meeting, 31 May-4 June 2013, Chicago, IL, USA. Abstract 9094.

${ }^{9}$ These authors are no longer employees of Exelixis.

Received 20 April 2016; revised 20 October 2016; accepted 14 November 2016; published online 19 January 2017 
treated populations, and induced durable responses, the majority of patients will eventually develop progressive melanoma and require additional therapy. In addition, the uveal melanoma subtype usually lacks BRAF mutations (Edmunds et al, 2003; Rimoldi et al, 2003), and with the exception of selumetinib, few data exist supporting the use of BRAF or MEK inhibitors in uveal melanoma (Carvajal et al, 2014). Pembrolizumab and ipilimumab have also shown signs of clinical activity in uveal melanoma in early phase trials (Kottschade et al, 2016; Oliva et al, 2016).

The receptor tyrosine kinase MET and its cognate ligand hepatocyte growth factor (HGF) have been implicated in diverse aspects of tumour pathobiology, including tumour growth, survival, neoangiogenesis, invasion, and dissemination (Gherardi et al, 2012). MET pathway activation and dysregulation have been implicated in multiple cancers, including melanoma. In a survey of 40 malignant melanoma specimens, MET expression and activation were evident in $88 \%$ and $21 \%$ of cases, respectively (Puri et al, 2007). In a genomic survey, the gene encoding MET was amplified and overexpressed in metastatic melanomas compared with primary melanomas (Kabbarah et al, 2010). In addition to the direct role of MET signalling in melanoma, HGF expression by stromal cells has been linked to innate resistance to RAF inhibitor treatment in melanoma patients. Moreover, amplification of the gene encoding MET has been implicated in acquired resistance to the BRAF inhibitor vemurafenib in cultured melanoma cells (Vergani et al, 2011; Straussman et al, 2012).

Uveal melanoma is a particularly treatment-resistant melanoma subtype that is often excluded from clinical trials because of perceived poor response rates, low survival, and a high incidence of liver metastases. However, MET may be a rational target for the uveal subtype. Mutations in the GNAQ and GNA11 genes, which encode guanine nucleotide-binding protein alpha subunits, are found in up to $83 \%$ of uveal melanomas (Van Raamsdonk et al, 2010). These mutations can lead to upregulation of MET, which is implicated in proliferation and migration of uveal melanoma cells (Patel et al, 2011; Yeh et al, 2011). In particular, preclinical evidence suggests that liver metastasis from uveal melanoma may be strongly dependent on the MET pathway (Patel et al, 2011; Yeh et al, 2011).

The receptor tyrosine kinase AXL is expressed in cutaneous and uveal primary melanomas and cell lines and regulates cell growth, survival, and migration (van Ginkel et al, 2004; Sensi et al, 2011). AXL expression negatively correlates with expression of microphthalmia-associated transcription factor (MITF), and a high AXL/ MITF ratio is associated with early resistance to BRAF inhibitors (Sensi et al, 2011; Muller et al, 2014).

Another protein that has a key role in melanoma is VEGF, as it is a central mediator of tumour angiogenesis and lymphangiogenesis (Carmeliet and Jain, 2011) and is dysregulated in melanoma. Circulating levels of VEGF, VEGFR1, and VEGFR3 are elevated in melanoma patients, and have been linked to poor prognosis (Tas et al, 2006; Mouawad et al, 2009).

Multiple agents that target VEGF signalling have been explored as monotherapy in melanoma, including bevacizumab, aflibercept, axitinib, vatalanib, sunitinib, dovitinib, and sorafenib; however, only a few demonstrated modest clinical activity (Nikolaou et al, 2012). The development of resistance to targeted monotherapy can limit clinical efficacy. A variety of preclinical models and clinical experience suggest that selective inhibition of VEGFR signalling may lead to a resistant phenotype (Ebos et al, 2009; Loges et al, 2009; Aftab and McDonald, 2011; Sennino et al, 2012) and imply that a multitargeted approach may be more effective. Indeed, combined inhibition of VEGFR and MET pathways resulted in enhanced efficacy over inhibition of either pathway alone in a mouse neuroendocrine tumour model (Sennino et al, 2012).

Cabozantinib (XL184; Exelixis, Inc.) is an orally bioavailable tyrosine kinase inhibitor that targets multiple receptor tyrosine kinases including MET, AXL, and VEGFRs. Cabozantinib potently inhibits HGF-induced migration and invasion of B16F10 melanoma cells (Yakes et al, 2011). Moreover, cabozantinib has shown activity in a xenograft model of uveal melanoma metastatic to the liver (Yeh et al, 2011). In a phase I clinical study, treatment with cabozantinib resulted in tumour reduction in multiple cancer types (Kurzrock et al, 2011).

The randomised discontinuation trial is used to determine the clinical activity of a therapeutic agent and minimise the use of placebo (Amery and Dony, 1975; Kopec et al, 1993). During the open-label phase, all patients receive the study medication for a predetermined time-period. Patients who achieve a tumour response continue open-label treatment, whereas those who achieve stable disease (SD) during the open-label phase are randomised to either continue treatment or receive placebo during the double-blind phase. The randomised discontinuation trial design enriches for a potentially sensitive population and then examines whether achieving SD was due to the therapeutic agent or selection of an indolent disease group (Stadler, 2009).

The current phase II placebo-controlled, randomised discontinuation trial of cabozantinib was conducted in nine selected tumour types, including castration-resistant prostate cancer, hepatocellular carcinoma, non-small-cell lung cancer, ovarian cancer, melanoma, and breast cancer (ClinicalTrials.gov: NCT00940225; Gordon et al, 2011). This report describes the results of this trial in the cohort of patients with melanoma, including cutaneous, uveal, and mucosal subtypes.

\section{MATERIALS AND METHODS}

Patients. Eligible patients had histologically confirmed melanoma (including cutaneous, uveal, and mucosal subtypes) with measurable disease by Response Evaluation Criteria in Solid Tumours (RECIST) version 1.0 (Therasse et al, 2000) and progressive disease at screening. Other eligibility requirements have been previously described and included a requirement for Eastern Cooperative Oncology Group (ECOG) performance status of 0 or 1 (Smith et al, 2013). Patients had no more than two prior standard or investigational chemotherapy or targeted therapy regimens in the metastic setting completed $\geqslant 4$ weeks before study entry. Radiotherapy and immunotherapy (such as IL-2 and immune checkpoint inhibitors) did not count towards this restriction. Patients with known brain metastases, radiation therapy within 2 weeks, or clinically significant intercurrent illness were excluded. The study was conducted in accordance with the Declaration of Helsinki and Good Clinical Practice guidelines. The study protocol and informed consent documents were reviewed and approved by the Institutional Review Boards of the participating institutions, and informed consent was obtained from all patients before any studyspecified procedures.

Study design. The primary endpoint of the lead-in phase was objective response rate at week 12, and the primary endpoint of the randomised phase was PFS. Secondary endpoints included assessing the safety and tolerability of the agent and potential pharmacodynamic effects. The study was designed as a randomised discontinuation trial (Ratain et al, 2006), and all patients received open-label cabozantinib treatment during a 12-week lead-in stage (Supplementary Figure S1). At week 12, patients with evidence of response by RECIST $(\geqslant 30 \%$ decrease in the sum of measurable lesions) remained on open-label cabozantinib, and patients with progressive disease (Therasse et al, 2000) were discontinued. Patients who did not meet the criteria for response or progression were judged to have SD and were randomised to either placebo or cabozantinib in double-blinded fashion. All randomised patients were followed until progression, at which point treatment 
assignment was unblinded; patients who were receiving cabozantinib were discontinued, and those receiving placebo were offered the opportunity to restart cabozantinib. Patients who chose to cross over to cabozantinib after progression on placebo were followed until their subsequent progression on open-label cabozantinib. The protocol was amended to add follow-up for OS. A study oversight committee monitored efficacy during the lead-in stage and had the ability to suspend randomisation based on the reviewed data. An independent data-monitoring committee monitored safety in the blinded randomised stage.

Study drug administration. Patients received cabozantinib at a daily oral dose of $100 \mathrm{mg}$ (free base equivalent weight) during a 12week open-label lead-in stage. Details of dosing interruptions have been previously described (Smith et al, 2013). If treatment was held to manage an adverse event (AE) related to treatment, cabozantinib was subsequently resumed at a reduced dose. Interruption in dosing for up to 3 weeks was allowed.

Study assessments. Safety parameters were evaluated every 3 weeks, and tumours were assessed every 6 weeks throughout the study. Efficacy assessments included radiographic soft tissue (by computed tomography (CT) or magnetic resonance imaging) and bone imaging by bone scan for patients with a history of bone metastasis. The PFS analysis was conducted based on investigator-assessed response by RECIST 1.0. Bone scan changes were assessed by an independent radiology facility (MedQIA; Los Angeles, CA, USA).

Other clinical assessments included medical and cancer history, physical examination, vital signs and body weight, electrocardiography, ECOG performance status, safety laboratories (serum chemistry, haematology, coagulation, and urinalysis), concomitant medications, AEs, and information on subsequent anticancer treatment. Other exploratory endpoints included analysis of changes in the circulating bone biomarker C-terminal cross-linked telopeptide of type I collagen (CTx), assessment of bone scan resolution (when applicable), and analysis of BRAF and/or GNAQ/GNA11 mutational status of tumour samples. The data cutoff date for the results presented in this publication was 16 December 2011.

Statistical considerations. The study employed an adaptive design. An SD rate of $35 \%$ in a cohort during the lead-in stage was selected as a reasonable response rate that indicated sufficient preliminary efficacy to evaluate the cohort further. Up to 200 patients could be enroled to a tumour type cohort to randomise 70 patients and achieve 52 events postrandomisation. This design provided $80 \%$ power to detect a hazard ratio of 0.5 for PFS after randomisation. Enrolment into a cohort could be halted if an insufficient number of patients had disease stabilisation due to either high or low rates of clinical activity during the lead-in stage. For the analysis of PFS from date of randomisation and OS from first dose, the Kaplan-Meier method was employed to estimate medians, and the log-rank test was used for inference testing. The Cox proportional hazards model was used to estimate hazard ratio. For the analysis of overall PFS from first dose, including the lead-in stage, the estimation method as described by Ratain et al (Ratain et al, 2006) was utilised. All treated patients contributed to the PFS estimate through the first 12 weeks. After week 12, the PFS was estimated as a weighted average of those continuing on openlabel treatment and those randomised to cabozantinib. The weights corresponded to the fraction of patients continuing on open-label treatment at week 12 and the proportion of patients randomised at week 12 (including placebo).

\section{RESULTS}

Patients. From September 2009 to November 2010, 77 patients with metastatic melanoma were enroled in the United States, Belgium, and Israel. Baseline demographic and clinical characteristics are summarised in Table 1 . Thirty per cent of patients had uveal melanoma, and $22 \%$ had bone metastases. Among the 54 patients with available mutation data, BRAF mutations were detected in $31 \%$. Sixty-six per cent of patients had at least one line of prior systemic therapy. During the 12 -week lead-in stage, 41 of the 77 enroled patients (53\%) discontinued study treatment primarily because of progressive disease (Figure 1). At week 12, 26 patients $(34 \%)$ were randomised to receive either cabozantinib or placebo, and 10 patients (13\%) continued open-label treatment with cabozantinib (Figure 1). Five of these 10 patients had experienced a partial response (PR); 4 of these were later determined to be confirmed PRs. The remaining five patients had SD at week 12 based on the final data analysis (Figure 1). Although the goal of the study was to randomise $\sim 70$ patients per cohort at week 12, randomisation was halted early by recommendation of the study oversight committee due to the high rates of tumour regression and the observation of symptomatic progression in individual patients randomised to placebo in several of the disease cohorts (Smith et al, 2013). Mean cabozantinib plasma concentration in patients who received at least 14 of 15 uninterrupted $100 \mathrm{mg}$ per day cabozantinib doses over the 2 weeks before the end of the week 6 pharmacokinetics sampling visit $(n=33)$ was $1118 \mathrm{ng} \mathrm{ml}^{-1}\left( \pm 542 \mathrm{ng} \mathrm{ml}^{-1}\right)$, with a corresponding per cent coefficient of variation of $48.5 \%$.

Response. The primary endpoint for the open-label, 12-week leadin stage of the study was response rate per RECIST 1.0. Among the 77 patients enroled in the lead-in stage, the objective response rate

Table 1. Baseline demographic and clinical characteristics of patients

\begin{tabular}{|c|c|}
\hline & Entire treated population $(N=77)$ \\
\hline Characteristic & $n(\%)$ \\
\hline \multicolumn{2}{|l|}{ Age (years) } \\
\hline Median & 65 \\
\hline Range & $30-90$ \\
\hline \multicolumn{2}{|l|}{ Sex } \\
\hline Male & $42(55)$ \\
\hline Female & $35(45)$ \\
\hline \multicolumn{2}{|l|}{ Melanoma subtype } \\
\hline Cutaneous & $48(62)$ \\
\hline Uveal & $23(30)$ \\
\hline Mucosal & $6(8)$ \\
\hline Bone metastases & $17(22)$ \\
\hline Known BRAF mutation & $17(31)^{a}$ \\
\hline \multicolumn{2}{|l|}{ Prior lines of therapy ${ }^{\mathbf{b}}$} \\
\hline 0 & $26(34)$ \\
\hline $1-2$ & $43(56)$ \\
\hline$\geqslant 3$ & $8(10)$ \\
\hline \multicolumn{2}{|l|}{ Prior therapies of interest } \\
\hline BRAF inhibitor & $6(8)$ \\
\hline MEK inhibitor & $3(4)$ \\
\hline Ipilimumab & $3(4)$ \\
\hline \multicolumn{2}{|c|}{ 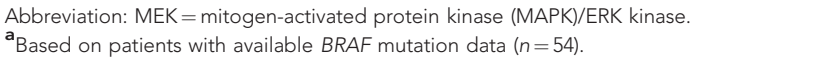 } \\
\hline \multirow{2}{*}{\multicolumn{2}{|c|}{$\begin{array}{l}{ }^{b_{T h}} \text { protocol limited prior therapies to } \leqslant 2 \text { prior standard or investigational chemotherapy } \\
\text { or targeted therapy regimens in the metastatic setting. }\end{array}$}} \\
\hline & \\
\hline \multicolumn{2}{|c|}{$\begin{array}{l}\text { Radiotherapy and immunotherapy (such as IL-2 and immune checkpoint inhibitors) did not } \\
\text { count towards this restriction. The number of prior therapies summarised here includes } \\
\text { therapies that did not count towards the limit of } \leqslant 2 \text { prior regimens. }\end{array}$} \\
\hline
\end{tabular}


at week 12 was $5 \%$, with 4 patients having a confirmed PR. An additional 30 patients had SD at week 12, resulting in a disease control rate $(\mathrm{PR}+\mathrm{SD})$ of $44 \%$. Eleven patients were not evaluable for response per RECIST due to the lack of adequate postbaseline scan data. Of 64 patients evaluable for change in measurable disease, 35 (55\%) had at least one assessment showing a reduction of measurable target lesions, including 13 of the 22 evaluable patients (59\%) with uveal melanoma (Figure 2). Reduction in measurable disease appeared to be independent of $B R A F$ mutation status.

Progression-free survival and overall survival. The primary endpoint for the randomised stage of the study was PFS after week 12 for patients with SD who were randomised to blinded treatment with cabozantinib or placebo. Twenty-six patients with SD at week 12 were randomised to cabozantinib $(n=13)$ or placebo $(n=13)$. The median PFS after randomisation at week 12 for cabozantinib patients was 4.1 months (95\% confidence interval $=1.8$ months, not reached), and 2.8 months for placebo patients ( $95 \%$ confidence interval $=1.5-5.5$ months), with a hazard ratio of 0.59 ( $P=0.284$; Figure $3 \mathrm{~A})$. Following documented disease progression, 12 patients in the placebo group elected to cross over to open-label cabozantinib therapy (Figure 1).

The median overall PFS for all treated patients $(N=77)$ over the entire treatment period from the start of therapy (week 1 day 1 ) was 3.8 months, and the PFS rate at month 6 was 33\% (Figure 3B). Median OS was 9.4 months for all treated patients (Figure 3C).

Uveal melanoma cohort. The melanoma cohort included 23 patients with metastatic uveal melanoma. The median age was 65 , and the median number of prior systemic anticancer regimens was one. Patients had substantial tumour burden at baseline, as reflected by a median sum of the longest diameter (SLD) of target lesions of $11.9 \mathrm{~cm}$ (range, 2.0-37.2), and hepatic metastases were present in 16 patients (70\%). The majority (9/10) of patient samples analysed for GNAQ/GNA11 mutation status harboured either a GNAQ $(n=5)$ or GNA11 mutation $(n=4)$ (Table 2). GNA11 status was unknown in the tissue sample from one patient with no detectable GNAQ mutation.

In the uveal melanoma cohort, $61 \%$ of patients $(14 / 23)$ had SD at week 12 , and no patient had a PR, resulting in an overall disease control rate of $61 \%$. The median PFS for the 23 patients with uveal melanoma was 4.8 months (41\% PFS rate at 6 months; Figure 3B),

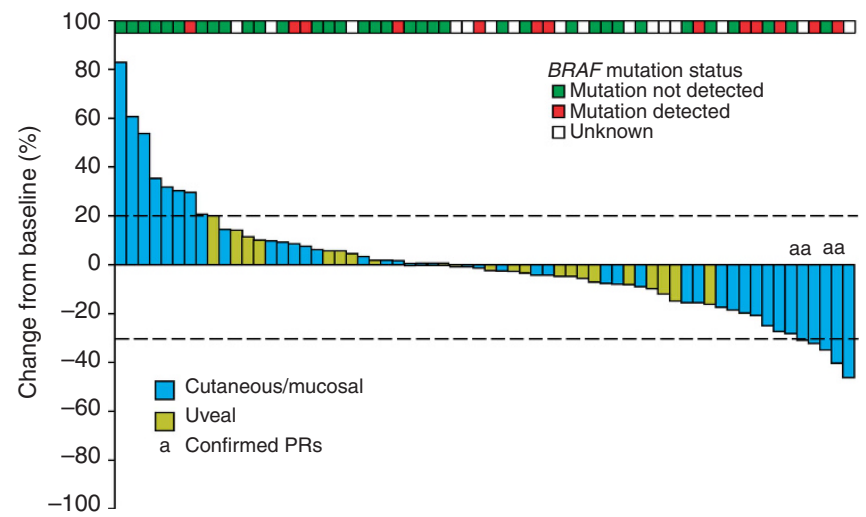

Figure 2. Best change from baseline in investigator-assessed measurements of target lesions using RECIST (version 1.0) was determined for patients who had baseline and at least one evaluable postbaseline radiographic scan in the first 12 weeks $(n=64)$. BRAF mutation status is based on sponsor analyses of archival tumour tissue and investigator reporting. RECIST = Response Evaluation Criteria in Solid Tumours.

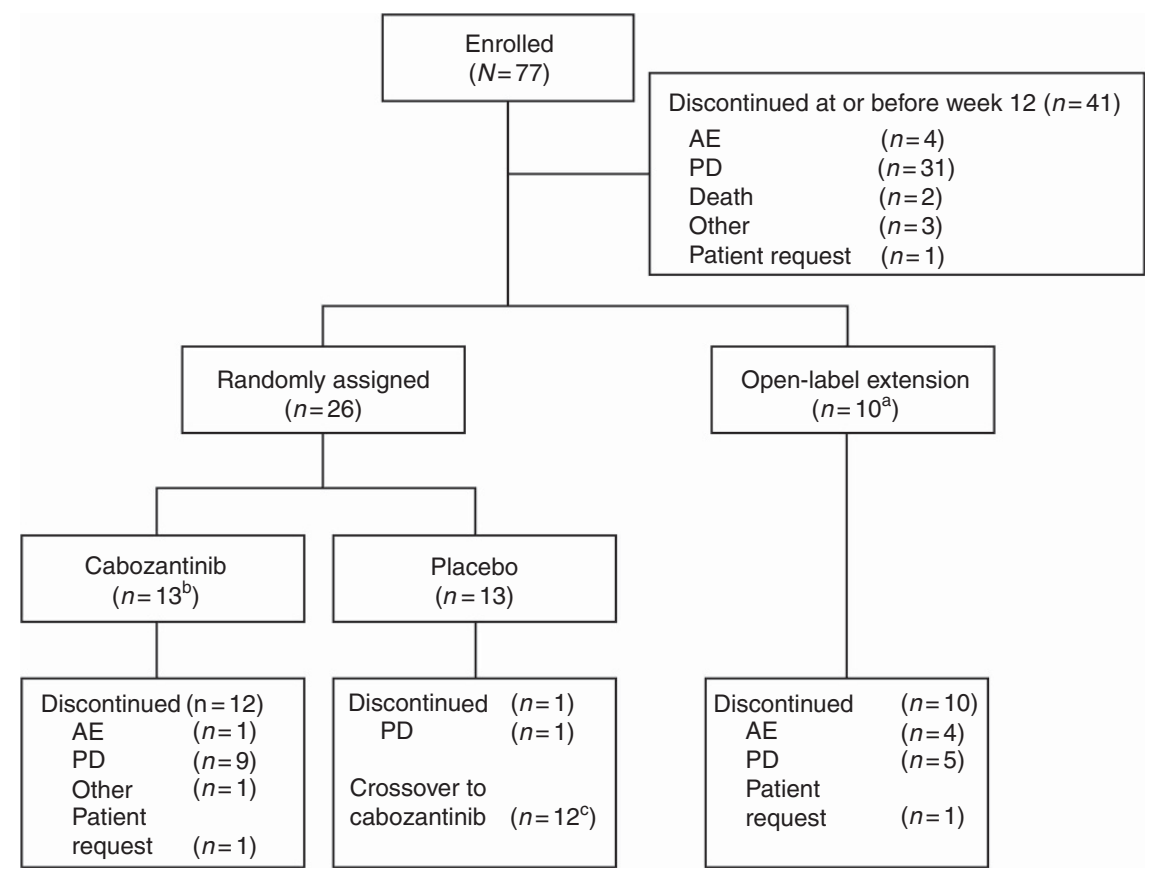

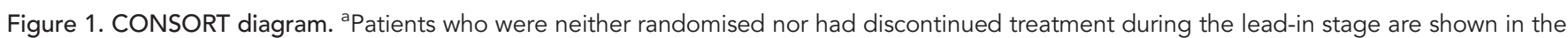
open-label continuation group, including five patients with SD at week 12 based on final data analysis. Randomisation was halted early by recommendation of the study oversight committee due to the high rates of tumour regression and the observation of symptomatic progression in individual patients randomised to placebo in several of the disease cohorts. ${ }^{b}$ One patient originally randomised to cabozantinib remained active at the time of the data cutoff. 'Twelve patients were randomly assigned to placebo and crossed over to open-label cabozantinib after unblinding. Four of those 12 patients remained active at the time of the data cutoff, and eight discontinued treatment (one patient request, one death, and six PD). CONSORT = Consolidated Standards of Reporting Trials; PD = progressive disease. 
and median OS was 12.6 months (Figure 3C). Most patients with uveal melanoma stayed on study treatment for $>4$ months, and six patients stayed on treatment for $>10$ months (Table 2). Two patients with uveal melanoma had bone metastases and a baseline bone scan, and both experienced partial resolution of their bone lesions during treatment with cabozantinib (Supplementary Figure S2). Both patients also experienced pain relief (per investigator) and had prolonged clinical benefit of $\sim 12$ and 6 months.

Because of the frequent occurrence and correlative morbidity and mortality of hepatic metastases observed in patients with uveal melanoma (Spagnolo et al, 2012), an additional exploratory analysis of best change in the SLDs of hepatic lesions through week 12 was performed for the 16 patients in the uveal cohort who had hepatic metastases at baseline. Among those patients, six experienced a decrease of any magnitude (range, 5-21\% decrease)
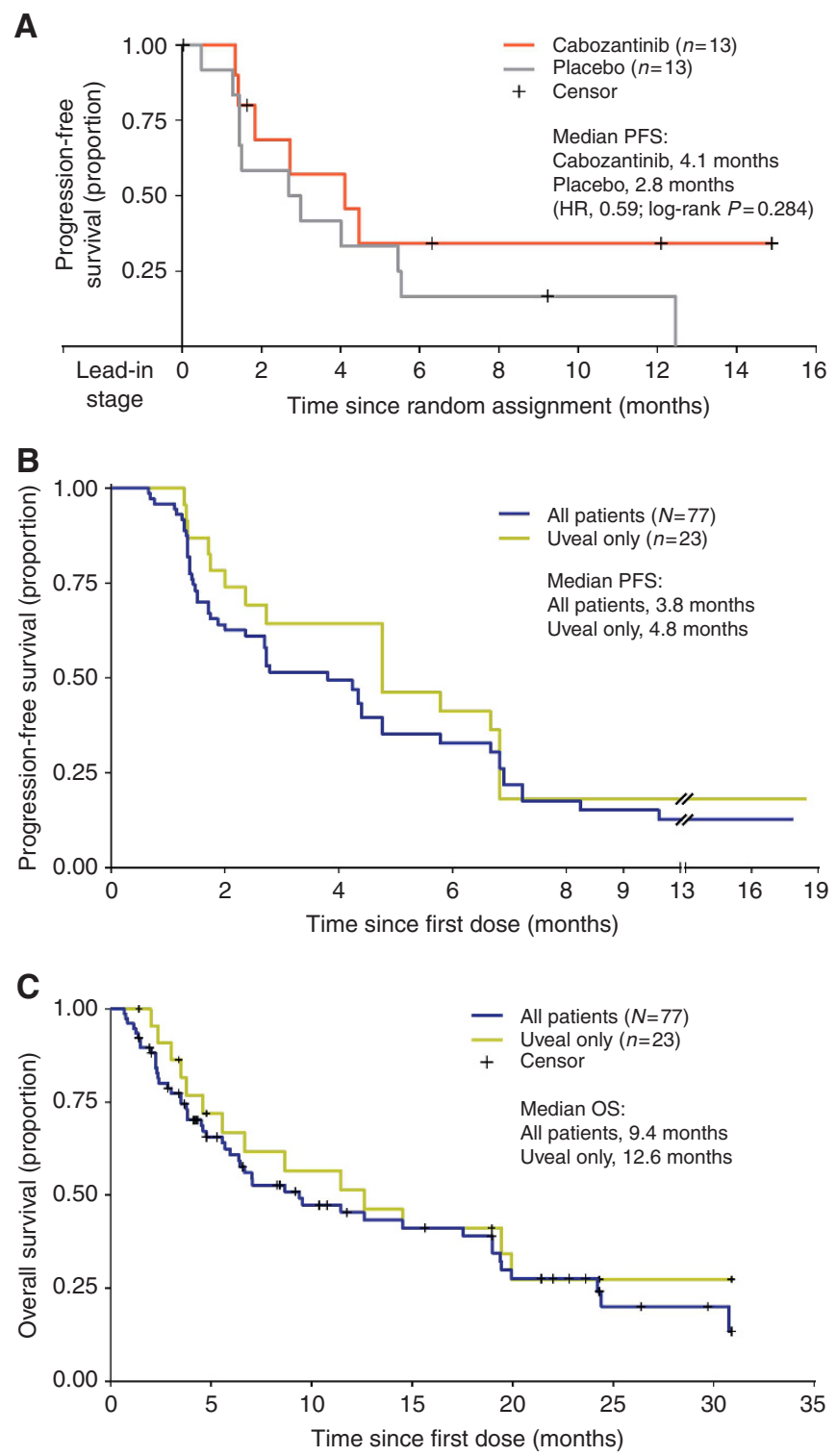

Figure 3. Estimates of PFS and OS. (A) PFS from week 12 in patients with melanoma who were randomly assigned to continue treatment with cabozantinib $(n=13)$ or placebo $(n=13)$. (B) PFS from first dose in all patients with metastatic melanoma $(N=77)$ and in patients with uveal melanoma $(n=23)$. (C) OS in all patients with metastatic melanoma $(N=77)$ and in patients with uveal melanoma $(n=23)$. $\mathrm{HR}=$ hazard ratio. in the SLD, two experienced no change, and eight experienced an increase of any magnitude (range, $2-28 \%$ increase). Five of the six patients with a decrease in SLD received treatment beyond the lead-in stage. All five of these patients were randomised to placebo at week 12, and in the absence of cabozantinib treatment, each of these patients experienced hepatic lesion growth at the subsequent assessment at week 18 .

Bone marker analysis. The bone resorption marker CTx is often elevated in patients with bone metastases and provides an objective measure of the effect of therapy on the rate of bone turnover. CTx levels were analysed in plasma samples from 13 patients with bone metastases. Eleven of these 13 patients had reductions in CTx ranging from 17 to $93 \%$, and seven of these 13 patients (54\%) had reductions of $>50 \%$ (Supplementary Figure S3). Two of these 13 patients were treated with bisphosphonate, and for both the reduction in CTx was $>80 \%$.

Safety. The most frequently reported AEs during the lead-in stage of the study, regardless of causality, are listed in Table 3 . The most common $(\geqslant 5 \%)$ grade $3 / 4$ events were fatigue $(14 \%)$, hypertension (10\%), abdominal pain (8\%), hand-foot syndrome (5\%), asthenia (5\%), back pain (5\%), and hypokalaemia (5\%). During the 12 -week lead-in stage, six patients (8\%) discontinued study treatment because of AEs. Two of these (3\%) were due to a grade 5 event: one patient died from peritonitis due to diverticular perforation (deemed related), and one patient died from an unknown cause (deemed unrelated). Twenty-two patients (29\%) had at least one dose reduction during the lead-in stage.

Table 2. GNAQ/GNA11 mutation status and time on study treatment in the 23 uveal melanoma patients

\begin{tabular}{|c|c|c|c|}
\hline Patient \# & $\begin{array}{l}\text { GNAQ } \\
\text { mutation }\end{array}$ & $\begin{array}{l}\text { GNA11 } \\
\text { mutation }\end{array}$ & $\begin{array}{c}\text { Months on study } \\
\text { treatment }^{\mathrm{a}}\end{array}$ \\
\hline 1 & UNK & UNK & $24.5+$ \\
\hline 2 & UNK & UNK & $19.9+$ \\
\hline 3 & UNK & UNK & $14.9+$ \\
\hline 4 & UNK & UNK & $14.6+$ \\
\hline 5 & UNK & UNK & 11.6 \\
\hline 6 & R1830 & ND & 10.3 \\
\hline 7 & UNK & UNK & 9.7 \\
\hline 8 & ND & Q209L & 8.7 \\
\hline 9 & UNK & UNK & 6.5 \\
\hline 10 & UNK & UNK & 5.0 \\
\hline 11 & UNK & UNK & 4.6 \\
\hline 12 & ND & UNK & 4.3 \\
\hline 13 & UNK & UNK & 3.5 \\
\hline 14 & ND & R183C & 3.0 \\
\hline 15 & Q209P & UNK & 3.0 \\
\hline 16 & Q209P & ND & 2.3 \\
\hline 17 & ND & Q209L & 2.1 \\
\hline 18 & Q209P & UNK & 1.8 \\
\hline 19 & UNK & UNK & 1.7 \\
\hline 20 & ND & Q209L & 1.4 \\
\hline 21 & Q209L & ND & 1.4 \\
\hline 22 & UNK & UNK & 1.4 \\
\hline 23 & UNK & UNK & 1.3 \\
\hline \multicolumn{4}{|c|}{$\begin{array}{l}\text { Abbreviations: } \mathrm{ND}=\text { not detected; } \mathrm{UNK}=\text { unknown. } \\
{ }^{\mathrm{a} M o n t h s} \text { with a plus }(+) \text { indicate patients who remain on study treatment as of the data } \\
\text { cutoff. }\end{array}$} \\
\hline
\end{tabular}


Table 3. Most frequently reported AEs during lead-in stage regardless of causality

\begin{tabular}{|c|c|c|}
\hline & $\begin{array}{l}\text { All grades } \\
(N=77)\end{array}$ & $\begin{array}{c}\text { Grade } \geqslant 3^{a} \\
(N=77)\end{array}$ \\
\hline$A E^{b}$ & $n(\%)$ & $n(\%)$ \\
\hline Fatigue & $46(60)$ & 11 (14) \\
\hline Diarrhoea & $44(57)$ & $2(3)$ \\
\hline Nausea & $39(51)$ & $1(1)$ \\
\hline Decreased appetite & $35(45)$ & $0(0)$ \\
\hline Abdominal pain & $24(31)$ & $6(8)$ \\
\hline Vomiting & $23(30)$ & $2(3)$ \\
\hline Hypertension & $22(29)$ & $8(10)$ \\
\hline Constipation & $20(26)$ & $3(4)$ \\
\hline Dysgeusia & $20(26)$ & $0(0)$ \\
\hline Hand-foot syndrome & $19(25)$ & $4(5)$ \\
\hline Stomatitis & $19(25)$ & $0(0)$ \\
\hline Aspartate aminotransferase increased & $17(22)$ & $2(3)$ \\
\hline Dry mouth & $17(22)$ & $0(0)$ \\
\hline Dysphonia & $17(22)$ & $0(0)$ \\
\hline Rash & $16(21)$ & $0(0)$ \\
\hline Weight decreased & $16(21)$ & $0(0)$ \\
\hline Dyspnoea & $13(17)$ & $3(4)$ \\
\hline Mucosal inflammation & $13(17)$ & $0(0)$ \\
\hline Alanine aminotransferase increased & $12(16)$ & $2(3)$ \\
\hline Hypomagnesaemia & $12(16)$ & $0(0)$ \\
\hline Asthenia & $11(14)$ & $4(5)$ \\
\hline Abdominal pain upper & $11(14)$ & $1(1)$ \\
\hline Dizziness & $11(14)$ & $1(1)$ \\
\hline Oral pain & $11(14)$ & $1(1)$ \\
\hline Urinary tract infection & $11(14)$ & $0(0)$ \\
\hline Back pain & $10(13)$ & $4(5)$ \\
\hline Hypokalaemia & $10(13)$ & $4(5)$ \\
\hline Pain in extremity & $10(13)$ & $3(4)$ \\
\hline Dry skin & 10 (13) & $0(0)$ \\
\hline \multicolumn{3}{|c|}{ 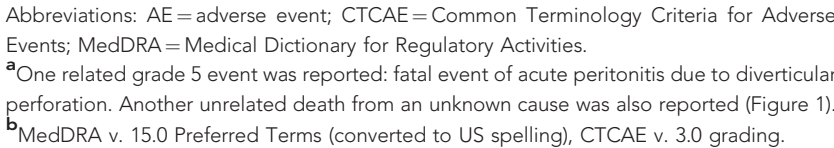 } \\
\hline
\end{tabular}

\section{DISCUSSION}

There have been remarkable advances recently in the treatment of patients with metastatic melanoma, including the development of inhibitors to immune checkpoint proteins and targeted therapies against the protein kinases BRAF and MEK. Ipilimumab, an antiCTLA4 antibody, and nivolumab and pembrolizumab, antibodies directed against PD-1, have demonstrated significant clinical activity in advanced melanoma including improvements in PFS and OS and induction of durable responses (Hodi et al, 2010; Robert et al, 2014; Larkin et al, 2015; Robert et al, 2015).

In a pivotal phase III randomised trial in patients with $B R A F$ mutant melanoma, vemurafenib achieved an objective response rate of $48 \%$ and median PFS of 5.3 months versus $5 \%$ and 1.6 months with dacarbazine, respectively (Chapman et al, 2011; Kudchadkar et al, 2013). Median OS was 13.2 months for vemurafenib versus 9.6 months for dacarbazine (Kudchadkar et al, 2013). Significantly improved PFS has been observed in
$B R A F$-mutant melanomas when BRAF and MEK inhibitors are used in combination (Larkin et al, 2014; Long et al, 2014); median PFS of 9.9 months was reported from a study of vemurafenib + cobimetinib, and PFS of 9.3 months was reported from a study of dabrafenib + trametinib. On extended follow-up, median OS for vemurafenib + cobimetinib was 22.3 months versus 17.4 months for vemurafenib alone, and median OS for dabrafenib + trametinib for 25.1 versus 18.7 months for dabrafenib alone (Flaherty et al, 2016; McArthur et al, 2016). However, the development of treatment resistance typically occurs after exposure to BRAF and MEK inhibitors, and there remains a need for additional treatment options. Also, it should be noted that only $\sim 50 \%$ of melanomas carry the BRAF mutation (Davies et al, 2002), and that BRAF mutations are very rare in uveal melanoma (Edmunds et al, 2003; Rimoldi et al, 2003).

There is a strong rationale for targeting MET, AXL, and VEGFRs in melanoma. MET activation, which may be driven by stromal HGF expression, has been shown to mediate melanoma growth, dissemination, and resistance to BRAF inhibition in multiple preclinical models (Puri et al, 2007; Kabbarah et al, 2010; Vergani et al, 2011; Straussman et al, 2012). AXL also regulates melanoma growth and migration and has been implicated in resistance to BRAF inhibition (van Ginkel et al, 2004; Sensi et al, 2011; Muller et al, 2014). VEGFR kinase inhibitors and anti-VEGF antibodies are part of standard therapy for numerous solid tumour malignancies and have been explored in melanoma (Nikolaou et al, 2012). Although activity has been observed with axitinib, pazopanib, and bevacizumab (Nikolaou et al, 2012), none of these agents have been approved in melanoma. Preclinical data indicate that a combination of VEGF pathway and MET inhibition can be effective in targeting tumour angiogenesis and suppressing tumour growth and metastasis (Shojaei et al, 2010; Aftab and McDonald, 2011; Sennino et al, 2012; Shojaei et al, 2012). We therefore included a cohort of metastatic melanoma patients in a randomised discontinuation trial designed to explore the activity of cabozantinib in nine solid tumour types.

The results of the current analysis demonstrate single-agent activity of cabozantinib in patients with uveal, cutaneous, or mucosal melanoma. At 12 weeks following the lead-in stage, the objective response rate by RECIST was modest (5\%); however, 57\% of patients experienced SD. Furthermore, the median OS (9.4 months), PFS (3.8 months), and PFS rate at 6 months (33\%) are noteworthy in this setting.

The current study was underpowered to detect a difference in PFS between cabozantinib and placebo because the number of patients randomised at 12 weeks did not achieve the protocolspecified number. Randomisation was halted early by recommendation of the study oversight committee due to the high rates of tumour regression and the observation of symptomatic progression in individual patients randomised to placebo in several of the disease cohorts.

Twenty-six melanoma patients with SD after 12 weeks of cabozantinib treatment were randomised to cabozantinib or placebo. Among these patients, cabozantinib treatment resulted in a median PFS of 4.1 months versus 2.8 months for placebo. The difference in PFS was not statistically significant, possibly due to the small number of randomised patients.

$B R A F$ mutation status was determined in available tumour tissue from 54 of the 77 enroled patients. There was no apparent association between BRAF mutation status and clinical outcome, and tumour reduction was observed in patients both with and without detectable BRAF mutations in their tumours. Interestingly, MET activation has been identified as a mechanism of resistance to BRAF inhibition in melanoma (Vergani et al, 2011). Therefore, it is reasonable to surmise that combining a BRAF inhibitor and cabozantinib may be a useful approach in patients with $B R A F$ mutation-positive tumours and may delay or prevent the 
development of resistance. However, future studies are needed to investigate this possibility.

Although the patient population was not deliberately enriched for uveal melanoma, this subtype represents a relatively high fraction of patients (30\%) given its low incidence, presumably due to the lack of effective treatment options. Uveal melanoma is typically associated with poor response rates, a high incidence of liver metastases (up to $90 \%$ of patients with metastatic disease), and a short median survival (3-5 months) (Patel et al, 2011; Spagnolo et al, 2012; Velho et al, 2012). Because of the lack of effective therapies for this disease, prognosis after the development of metastases is poor (Spagnolo et al, 2012; Velho et al, 2012). For example, the median OS for patients with metastatic uveal melanoma may be as little as 3.6 months, and 5-year OS as low as $1 \%$ has been reported (Patel et al, 2011). In contrast, the median OS for the 23 patients with metastatic uveal melanoma enroled in our study was 12.6 months and the median PFS was 4.8 months, thereby suggesting potential for clinical activity with cabozantinib in this melanoma subtype.

The most frequent AEs in this cohort (e.g., fatigue, diarrhoea, nausea, and decreased appetite) were mainly mild to moderate in severity and were consistent with those observed in the other cohorts in the RDT. A similar safety profile is observed with other VEGFR inhibitors, and AEs are generally managed with dose holds and reductions and supportive care.

In this randomised discontinuation trial of cabozantinib, clinical activity was observed in a cohort of patients with metastatic melanoma, and toxicity was manageable and consistent with other multikinase inhibitors. The data from this trial also highlight the potential benefits of cabozantinib on both soft tissue and bone lesions in patients with metastatic melanoma. Treatment with cabozantinib was associated with encouraging PFS and OS, and reduction in the size of measurable target lesions was observed in the majority of patients with uveal, cutaneous, and mucosal melanoma. Clinical activity appeared to be independent of $B R A F$ mutation status. Overall, these data suggest that targeting the VEGFR, MET, and AXL pathways with cabozantinib may lead to improved outcomes in patients with metastatic melanoma. However, because this phase II randomised discontinuation trial was underpowered to draw definitive conclusions in the cohort of patients with metastatic melanoma, additional studies of cabozantinib in this patient population are needed to confirm these results.

\section{ACKNOWLEDGEMENTS}

We thank the members of the independent safety data-monitoring committee (Christopher Nutting, Ralph D'Agostino, Joseph Leach, and Axel Grothey); the study medical monitor David Ramies (Exelixis, Inc.); Bridget O'Keeffe, Paul Foster, Thomas Stout, Jaymes Holland, Teresa Rafferty, Douglas Laird, Colin Hessel, and Yihua Lee (Exelixis, Inc.), who assisted greatly in facilitating data management and analysis; Dana Aftab (Exelixis, Inc.) for his scientific support; and Gisela Schwab and Peter Lamb (Exelixis, Inc.) for their critical review of the manuscript. We thank Michael Hobert, PhD, Scientific Strategy Partners, Inc., for medical editorial assistance with this manuscript. Clinical Trials Registration Number: NCT00940225. Available at: http://www.clinicaltrials.gov/show/NCT00940225.

\section{CONFLICT OF INTEREST}

The authors declare no conflict of interest.

\section{AUTHOR CONTRIBUTIONS}

Research funding and financial support for medical editorial assistance were provided by Exelixis, Inc. AD, HK, RK, TS, AM and GS have received research funding from Exelixis to their respective institutions for the conduct of the study. MG is a consultant for Exelixis and has received research funding from Exelixis. ALW and FS are employees and stockholders of Exelixis; FS has a patent pending related to this subject matter.

\section{REFERENCES}

Aftab DT, McDonald DM (2011) MET and VEGF: synergistic targets in castration-resistant prostate cancer. Clin Transl Oncol 13(10): 703-709.

Amery W, Dony J (1975) A clinical trial design avoiding undue placebo treatment. J Clin Pharmacol 15(10): 674-679.

Carmeliet P, Jain RK (2011) Molecular mechanisms and clinical applications of angiogenesis. Nature 473(7347): 298-307.

Carvajal RD, Sosman JA, Quevedo JF, Milhem MM, Joshua AM, Kudchadkar RR, Linette GP, Gajewski TF, Lutzky J, Lawson DH, Lao CD, Flynn PJ, Albertini MR, Sato T, Lewis K, Doyle A, Ancell K, Panageas KS, Bluth M, Hedvat C, Erinjeri J, Ambrosini G, Marr B, Abramson DH, Dickson MA, Wolchok JD, Chapman PB, Schwartz GK (2014) Effect of selumetinib vs chemotherapy on progression-free survival in uveal melanoma: a randomized clinical trial. JAMA 311(23): 2397-2405.

Chapman PB, Hauschild A, Robert C, Haanen JB, Ascierto P, Larkin J, Dummer R, Garbe C, Testori A, Maio M, Hogg D, Lorigan P, Lebbe C, Jouary T, Schadendorf D, Ribas A, O’Day SJ, Sosman JA, Kirkwood JM, Eggermont AM, Dreno B, Nolop K, Li J, Nelson B, Hou J, Lee RJ, Flaherty KT, McArthur GA (2011) Improved survival with vemurafenib in melanoma with BRAF V600E mutation. N Engl J Med 364(26): 2507-2516.

Davies H, Bignell GR, Cox C, Stephens P, Edkins S, Clegg S, Teague J, Woffendin H, Garnett MJ, Bottomley W, Davis N, Dicks E, Ewing R, Floyd Y, Gray K, Hall S, Hawes R, Hughes J, Kosmidou V, Menzies A, Mould C, Parker A, Stevens C, Watt S, Hooper S, Wilson R, Jayatilake H, Gusterson BA, Cooper C, Shipley J, Hargrave D, Pritchard-Jones K, Maitland N, Chenevix-Trench G, Riggins GJ, Bigner DD, Palmieri G, Cossu A, Flanagan A, Nicholson A, Ho JW, Leung SY, Yuen ST, Weber BL, Seigler HF, Darrow TL, Paterson H, Marais R, Marshall CJ, Wooster R, Stratton MR, Futreal PA (2002) Mutations of the BRAF gene in human cancer. Nature 417(6892): 949-954.

Ebos JM, Lee CR, Cruz-Munoz W, Bjarnason GA, Christensen JG, Kerbel RS (2009) Accelerated metastasis after short-term treatment with a potent inhibitor of tumor angiogenesis. Cancer Cell 15(3): 232-239.

Edmunds SC, Cree IA, Di Nicolantonio F, Hungerford JL, Hurren JS, Kelsell DP (2003) Absence of BRAF gene mutations in uveal melanomas in contrast to cutaneous melanomas. Br J Cancer 88(9): 1403-1405.

Flaherty K, Davies MA, Grob JJ, Long GV, Nathan PD, Ribas A, Robert C, Schadendorf D, Frederick DT, Hammond MR, Jane-Valbuena J, Mu X, Squires M, Jaeger SA, Lane SR, Mookerjee B, Garraway LA (2016) Genomic analysis and 3-y efficacy and safety update of COMBI-d: A phase 3 study of dabrafenib (D) + trametinib (T) vs D monotherapy in patients (pts) with unresectable or metastatic BRAF V600E/K-mutant cutaneous melanoma. J Clin Oncol 34(suppl): Abstract 9502.

Gherardi E, Birchmeier W, Birchmeier C, Vande Woude G (2012) Targeting MET in cancer: rationale and progress. Nat Rev Cancer 12(2): 89-103.

Gordon MS, Vogelzang NJ, Schoffski P, Daud A, Spira AI, O'Keeffe BA, Rafferty T, Lee Y, Berger R, Shapiro G (2011) Activity of cabozantinib (XL184) in soft tissue and bone: Results of a phase II randomized discontinuation trial (RDT) in patients (pts) with advanced solid tumors. J Clin Oncol 29(suppl): Abstract 3010.

Hauschild A, Grob JJ, Demidov LV, Jouary T, Gutzmer R, Millward M, Rutkowski P, Blank CU, Miller Jr. WH, Kaempgen E, Martin-Algarra S, Karaszewska B, Mauch C, Chiarion-Sileni V, Martin AM, Swann S, Haney P, Mirakhur B, Guckert ME, Goodman V, Chapman PB (2012) Dabrafenib in BRAF-mutated metastatic melanoma: a multicentre, openlabel, phase 3 randomised controlled trial. Lancet 380(9839): 358-365. Hodi FS, O'Day SJ, McDermott DF, Weber RW, Sosman JA, Haanen JB, Gonzalez R, Robert C, Schadendorf D, Hassel JC, Akerley W, van den Eertwegh AJ, Lutzky J, Lorigan P, Vaubel JM, Linette GP, Hogg D, 
Ottensmeier CH, Lebbe C, Peschel C, Quirt I, Clark JI, Wolchok JD, Weber JS, Tian J, Yellin MJ, Nichol GM, Hoos A, Urba WJ (2010) Improved survival with ipilimumab in patients with metastatic melanoma. $N$ Engl J Med 363(8): 711-723.

Kabbarah O, Nogueira C, Feng B, Nazarian RM, Bosenberg M, Wu M, Scott KL, Kwong LN, Xiao Y, Cordon-Cardo C, Granter SR, Ramaswamy S, Golub T, Duncan LM, Wagner SN, Brennan C, Chin L (2010) Integrative genome comparison of primary and metastatic melanomas. PLoS One 5(5): e10770.

Kopec JA, Abrahamowicz M, Esdaile JM (1993) Randomized discontinuation trials: utility and efficiency. J Clin Epidemiol 46(9): 959-971.

Kottschade LA, McWilliams RR, Markovic SN, Block MS, Villasboas Bisneto J, Pham AQ, Esplin BL, Dronca RS (2016) The use of pembrolizumab for the treatment of metastatic uveal melanoma. Melanoma Res 26(3): 300-303.

Kudchadkar RR, Smalley KS, Glass LF, Trimble JS, Sondak VK (2013) Targeted therapy in melanoma. Clin Dermatol 31(2): 200-208.

Kurzrock R, Sherman SI, Ball DW, Forastiere AA, Cohen RB, Mehra R, Pfister DG, Cohen EE, Janisch L, Nauling F, Hong DS, Ng CS, Ye L, Gagel RF, Frye J, Muller T, Ratain MJ, Salgia R (2011) Activity of XL184 (Cabozantinib), an oral tyrosine kinase inhibitor, in patients with medullary thyroid cancer. J Clin Oncol 29(19): 2660-2666.

Larkin J, Ascierto PA, Dreno B, Atkinson V, Liszkay G, Maio M, Mandala M, Demidov L, Stroyakovskiy D, Thomas L, de la Cruz-Merino L, Dutriaux C, Garbe C, Sovak MA, Chang I, Choong N, Hack SP, McArthur GA, Ribas A (2014) Combined vemurafenib and cobimetinib in BRAFmutated melanoma. N Engl J Med 371(20): 1867-1876.

Larkin J, Chiarion-Sileni V, Gonzalez R, Grob JJ, Cowey CL, Lao CD, Schadendorf D, Dummer R, Smylie M, Rutkowski P, Ferrucci PF, Hill A, Wagstaff J, Carlino MS, Haanen JB, Maio M, Marquez-Rodas I, McArthur GA, Ascierto PA, Long GV, Callahan MK, Postow MA, Grossmann K, Sznol M, Dreno B, Bastholt L, Yang A, Rollin LM, Horak C, Hodi FS, Wolchok JD (2015) Combined nivolumab and ipilimumab or monotherapy in untreated melanoma. N Engl J Med 373(1): 23-34.

Loges S, Mazzone M, Hohensinner P, Carmeliet P (2009) Silencing or fueling metastasis with VEGF inhibitors: antiangiogenesis revisited. Cancer Cell 15(3): 167-170.

Long GV, Stroyakovskiy D, Gogas H, Levchenko E, de Braud F, Larkin J, Garbe C, Jouary T, Hauschild A, Grob JJ, Chiarion Sileni V, Lebbe C, Mandala M, Millward M, Arance A, Bondarenko I, Haanen JB, Hansson J, Utikal J, Ferraresi V, Kovalenko N, Mohr P, Probachai V, Schadendorf D, Nathan P, Robert C, Ribas A, DeMarini DJ, Irani JG, Casey M, Ouellet D, Martin AM, Le N, Patel K, Flaherty K (2014) Combined BRAF and MEK inhibition versus BRAF inhibition alone in melanoma. $N$ Engl J Med 371(20): 1877-1888.

McArthur GA, Larkin JMG, Ascierto PA, Hsu JJ, Yan Y, Rooney IA, Koralek DO, Dréno B, Ribas A (2016) Efficacy of cobimetinib (C) and vemurafenib (V) in advanced $B R A F$-mutated melanoma patients (pts) with poor and favorable prognosis in the coBRIM phase III study. J Clin Oncol 34(suppl): Abstract 9530.

Mouawad R, Spano JP, Comperat E, Capron F, Khayat D (2009) Tumoural expression and circulating level of VEGFR-3 (Flt-4) in metastatic melanoma patients: correlation with clinical parameters and outcome. Eur J Cancer 45(8): 1407-1414.

Muller J, Krijgsman O, Tsoi J, Robert L, Hugo W, Song C, Kong X, Possik PA, Cornelissen-Steijger PD, Geukes Foppen MH, Kemper K, Goding CR, McDermott U, Blank C, Haanen J, Graeber TG, Ribas A, Lo RS, Peeper DS (2014) Low MITF/AXL ratio predicts early resistance to multiple targeted drugs in melanoma. Nat Commun 5: 5712.

Nikolaou VA, Stratigos AJ, Flaherty KT, Tsao H (2012) Melanoma: new insights and new therapies. J Invest Dermatol 132(3 Pt 2): 854-863.

Oliva M, Rullan AJ, Piulats JM (2016) Uveal melanoma as a target for immune-therapy. Ann Transl Med 4(9): 172.

Patel M, Smyth E, Chapman PB, Wolchok JD, Schwartz GK, Abramson DH, Carvajal RD (2011) Therapeutic implications of the emerging molecular biology of uveal melanoma. Clin Cancer Res 17(8): 2087-2100.

Puri N, Ahmed S, Janamanchi V, Tretiakova M, Zumba O, Krausz T, Jagadeeswaran R, Salgia R (2007) c-Met is a potentially new therapeutic target for treatment of human melanoma. Clin Cancer Res 13(7): 2246-2253.
Ratain MJ, Eisen T, Stadler WM, Flaherty KT, Kaye SB, Rosner GL, Gore M, Desai AA, Patnaik A, Xiong HQ, Rowinsky E, Abbruzzese JL, Xia C, Simantov R, Schwartz B, O’Dwyer PJ (2006) Phase II placebo-controlled randomized discontinuation trial of sorafenib in patients with metastatic renal cell carcinoma. J Clin Oncol 24(16): 2505-2512.

Rimoldi D, Salvi S, Lienard D, Lejeune FJ, Speiser D, Zografos L, Cerottini JC (2003) Lack of BRAF mutations in uveal melanoma. Cancer Res 63(18): $5712-5715$.

Robert C, Long GV, Brady B, Dutriaux C, Maio M, Mortier L, Hassel JC, Rutkowski P, McNeil C, Kalinka-Warzocha E, Savage KJ, Hernberg MM, Lebbe C, Charles J, Mihalcioiu C, Chiarion-Sileni V, Mauch C, Cognetti F, Arance A, Schmidt H, Schadendorf D, Gogas H, Lundgren-Eriksson L, Horak C, Sharkey B, Waxman IM, Atkinson V, Ascierto PA (2015) Nivolumab in previously untreated melanoma without BRAF mutation. $N$ Engl J Med 372(4): 320-330.

Robert C, Ribas A, Wolchok JD, Hodi FS, Hamid O, Kefford R, Weber JS, Joshua AM, Hwu WJ, Gangadhar TC, Patnaik A, Dronca R, Zarour H, Joseph RW, Boasberg P, Chmielowski B, Mateus C, Postow MA, Gergich K, Elassaiss-Schaap J, Li XN, Iannone R, Ebbinghaus SW, Kang SP, Daud A (2014) Anti-programmed-death-receptor-1 treatment with pembrolizumab in ipilimumab-refractory advanced melanoma: a randomised dose-comparison cohort of a phase 1 trial. Lancet 384(9948): 1109-1117.

Sennino B, Ishiguro-Oonuma T, Wei Y, Naylor RM, Williamson CW, Bhagwandin V, Tabruyn SP, You WK, Chapman HA, Christensen JG, Aftab DT, McDonald DM (2012) Suppression of tumor invasion and metastasis by concurrent inhibition of c-Met and VEGF signaling in pancreatic neuroendocrine tumors. Cancer Discov 2(3): 270-287.

Sensi M, Catani M, Castellano G, Nicolini G, Alciato F, Tragni G, De Santis G, Bersani I, Avanzi G, Tomassetti A, Canevari S, Anichini A (2011) Human cutaneous melanomas lacking MITF and melanocyte differentiation antigens express a functional Axl receptor kinase. J Invest Dermatol 131(12): 2448-2457.

Shojaei F, Lee JH, Simmons BH, Wong A, Esparza CO, Plumlee PA, Feng J, Stewart AE, Hu-Lowe DD, Christensen JG (2010) HGF/c-Met acts as an alternative angiogenic pathway in sunitinib-resistant tumors. Cancer Res 70(24): 10090-10100.

Shojaei F, Simmons BH, Lee JH, Lappin PB, Christensen JG (2012) HGF/cMet pathway is one of the mediators of sunitinib-induced tumor cell typedependent metastasis. Cancer Lett 320(1): 48-55.

Smith DC, Smith MR, Sweeney C, Elfiky AA, Logothetis C, Corn PG, Vogelzang NJ, Small EJ, Harzstark AL, Gordon MS, Vaishampayan UN, Haas NB, Spira AI, Lara Jr. PN, Lin CC, Srinivas S, Sella A, Schoffski P, Scheffold C, Weitzman AL, Hussain M (2013) Cabozantinib in patients with advanced prostate cancer: results of a phase II randomized discontinuation trial. J Clin Oncol 31(4): 412-419.

Sosman JA, Kim KB, Schuchter L, Gonzalez R, Pavlick AC, Weber JS, McArthur GA, Hutson TE, Moschos SJ, Flaherty KT, Hersey P, Kefford R, Lawrence D, Puzanov I, Lewis KD, Amaravadi RK, Chmielowski B, Lawrence HJ, Shyr Y, Ye F, Li J, Nolop KB, Lee RJ, Joe AK, Ribas A (2012) Survival in BRAF V600-mutant advanced melanoma treated with vemurafenib. N Engl J Med 366(8): 707-714.

Spagnolo F, Caltabiano G, Queirolo P (2012) Uveal melanoma. Cancer Treat Rev 38(5): 549-553.

Stadler W (2009) Other paradigms: randomized discontinuation trial design. Cancer J 15(5): 431-434.

Straussman R, Morikawa T, Shee K, Barzily-Rokni M, Qian ZR, Du J, Davis A, Mongare MM, Gould J, Frederick DT, Cooper ZA, Chapman PB, Solit DB, Ribas A, Lo RS, Flaherty KT, Ogino S, Wargo JA, Golub TR (2012) Tumour micro-environment elicits innate resistance to RAF inhibitors through HGF secretion. Nature 487(7408): 500-504.

Tas F, Duranyildiz D, Oguz H, Camlica H, Yasasever V, Topuz E (2006) Circulating serum levels of angiogenic factors and vascular endothelial growth factor receptors 1 and 2 in melanoma patients. Melanoma Res 16(5): 405-411.

Therasse P, Arbuck SG, Eisenhauer EA, Wanders J, Kaplan RS, Rubinstein L, Verweij J, Van Glabbeke M, van Oosterom AT, Christian MC, Gwyther SG (2000) New guidelines to evaluate the response to treatment in solid tumors. European Organization for Research and Treatment of Cancer, National Cancer Institute of the United States, National Cancer Institute of Canada. J Natl Cancer Inst 92(3): 205-216.

Tsao H, Atkins MB, Sober AJ (2004) Management of cutaneous melanoma. N Engl J Med 351(10): 998-1012. 
van Ginkel PR, Gee RL, Shearer RL, Subramanian L, Walker TM, Albert DM, Meisner LF, Varnum BC, Polans AS (2004) Expression of the receptor tyrosine kinase Axl promotes ocular melanoma cell survival. Cancer Res 64(1): 128-134.

Van Raamsdonk CD, Griewank KG, Crosby MB, Garrido MC, Vemula S, Wiesner T, Obenauf AC, Wackernagel W, Green G, Bouvier N, Sozen MM, Baimukanova G, Roy R, Heguy A, Dolgalev I, Khanin R, Busam K, Speicher MR, O'Brien J, Bastian BC (2010) Mutations in GNA11 in uveal melanoma. N Engl J Med 363(23): 2191-2199.

Velho TR, Kapiteijn E, Jager MJ (2012) New therapeutic agents in uveal melanoma. Anticancer Res 32(7): 2591-2598.

Vergani E, Vallacchi V, Frigerio S, Deho P, Mondellini P, Perego P, Cassinelli G, Lanzi C, Testi MA, Rivoltini L, Bongarzone I, Rodolfo M (2011) Identification of MET and SRC activation in melanoma cell lines showing primary resistance to PLX4032. Neoplasia 13(12): 1132-1142.
Yakes FM, Chen J, Tan J, Yamaguchi K, Shi Y, Yu P, Qian F, Chu F, Bentzien F, Cancilla B, Orf J, You A, Laird AD, Engst S, Lee L, Lesch J, Chou YC, Joly AH (2011) Cabozantinib (XL184), a novel MET and VEGFR2 inhibitor, simultaneously suppresses metastasis, angiogenesis, and tumor growth. Mol Cancer Ther 10(12): 2298-2308.

Yeh I, Griewank K, Ding VW, Bastian BC (2011) XL184: c-Met inhibition is effective in a mouse xenograft model of metastatic uveal melanoma. Cancer Res 71(8 suppl 1): Abstract 3587.

(c) (i) This work is licensed under the Creative Commons Attribution 4.0 International License. To view a copy

(C) The Author(s) named above 2017

Supplementary Information accompanies this paper on British Journal of Cancer website (http://www.nature.com/bjc) 